\title{
Cocaine- and amphetamine-regulated transcript: a novel regulator of energy homeostasis expressed in a subpopulation of pancreatic islet cells
}

\author{
Patrick Gilon $^{1}$
}

Received: 10 June 2016 / Accepted: 28 June 2016 / Published online: 15 July 2016

(C) Springer-Verlag Berlin Heidelberg 2016

\begin{abstract}
Type 2 diabetes is characterised by chronic hyperglycaemia and its incidence is highly increased by exaggerated food consumption. It results from a lack of insulin action/production, but growing evidence suggests that it might also involve hyperglucagonaemia and impaired control of glucose homeostasis by the brain. In recent years, the cocaine and amphetamine-regulated transcript (CART) peptides have generated a lot of interest in the battle against obesity because, via the brain, they exert anorexic effects and they increase energy expenditure. They are also localised, outside the brain, in discrete regions of the body and play a hormonal role in controlling various functions. In this issue of Diabetologia, the Wierup group (doi: 10.1007/s00125-016-4020-6) shows that CART peptides are expressed heterogeneously in islet cells of various species, including humans, and that their expression is upregulated in diabetes. The authors also shine a spotlight on some interesting effects of CART peptides on islet function, including stimulation of insulin secretion and inhibition of glucagon release. CART peptides would thus be at the centre of a cooperation between the brain and the endocrine pancreas to control glucose homeostasis. Although the mechanisms of action of CART peptides remain enigmatic because no specific receptor for these peptides has so far been discovered, their potential therapeutic use is evident and represents a new challenge for future research.
\end{abstract}

Patrick Gilon

patrick.gilon@uclouvain.be

1 Pôle d'endocrinologie, diabète et nutrition, Institut de Recherche Expérimentale et Clinique, Université Catholique de Louvain, Avenue Hippocrate 55, B1.55.06, 1200 Brussels, Belgium
Keywords Anorexigenic · Brain · CART-peptide · Cocaineand amphetamine-regulated transcript · Glucagon · Insulin . Islets · Type 2 diabetes
Abbreviations
Arc Arcuate nucleus
$\left[\mathrm{Ca}^{2+}\right]_{\mathrm{c}}$ Free cytosolic $\mathrm{Ca}^{2+}$ concentration
CART Cocaine- and amphetamine-regulated transcript
GLP-1 Glucagon-like-peptide-1
TRH Thyrotropin releasing hormone

\section{Introduction}

Glucose homeostasis results from a fine tuned balance between intake, elimination, storage, production and utilisation of fuels linked to glucose metabolism. It is affected by a change in flux of any of these processes. Type 2 diabetes, which is diagnosed based on impaired glucose homeostasis, mainly occurs as a result of impaired insulin production and action, but recent evidence infers that hyperglucagonaemia and impaired blood glucose control by the brain are also responsible [1-3]. Weight gain and obesity are risk factors for type 2 diabetes.

In order to cure type 2 diabetes, an ideal drug would correct all the defects induced by the disease. Such a drug does not yet exist, but some of them exert multiple beneficial effects, including those which target the glucagon-like-peptide-1 (GLP-1) receptor or those that block its degradation. The GLP-1-based therapeutics improve glucose homeostasis by stimulating insulin secretion, promoting beta cell survival and proliferation, decreasing glucagonaemia, and producing anorexic effects [4-6]. In this issue of Diabetologia, the Wierup group (with Abels as first author) shows that cocaine- and amphetamine- 
regulated transcript (CART) peptides stimulate insulin secretion and inhibit glucagon release from human and mouse islets [7]. Because these peptides also induce weight loss and increase energy expenditure, the authors suggest that CART peptides or their mimetics might be promising agents to combat diabetes.

\section{Synthesis and processing of CART peptides}

The designation 'CART' comes from previous experiments which showed that administration of cocaine or amphetamine in rodents upregulated a particular mRNA that was named Cart (encoded by the Cartpt gene), which produces peptides referred to as CART peptides [8,9]. In rats, the Cartpt gene is transcribed into two alternatively spliced mRNAs of different lengths, producing two different peptides; pro-CART 1-102 and pro-CART 1-89 (Fig. 1). Nonetheless, this mRNA splicing does not affect the activity of resultant CART peptides because their active parts are encoded by regions that lie downstream of the spliced region. CART peptides are processed in a tissue-specific manner by pro-hormone convertases into several peptides, at least two of which are biologically active. In rats, the bioactive peptides derived from pro-CART 1-102 are CART 55-102 and CART 62-102. Although the bioactive peptides derived from pro-CART 1-89 are numbered differently than those derived from pro-CART 1-102, namely CART $42-89$ and 49-89, their amino acid sequences are identical to those derived from pro-CART 1-102. As a result, some confusion is present in the literature because the same proteins (with the same amino acid sequences) are classified differently. Therefore, the bioactive peptides are interchangeably called CART 55-102 or CART 42-89, and CART 62-102 or CART 49-89. Humans only produce pro-CART

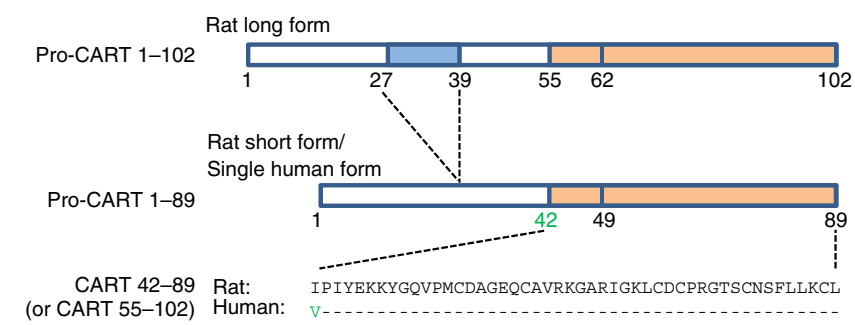

Fig. 1 Amino acid numbering of rat and human pro-CART and CART peptides. In the rat, the Cartpt gene produces two mRNA splice variants, one that encodes a long form of pro-CART (pro-CART 1-102) and one that encodes a short form (pro-CART 1-89). The amino acid sequences are similar in both forms except for 13 amino acids (highlighted in blue), which are spliced out in the short form. The bioactive fragments lie in the carboxyl-terminal parts, shown in beige. The amino acid sequences of the bioactive peptides are similar in the long and short forms of pro-CART, but they are numbered differently. Only the short form is found in humans and only amino acid 42 (highlighted in green) is different between the bioactive forms of rats and humans
1-89, the bioactive forms of which are similar to those of rats, except for the first amino acid of the long bioactive form (CART 42-89). Unless otherwise specified, 'CART' will be used hereafter to refer to any of either rat or human bioactive peptides.

\section{CART secretion and transduction pathways activated by CART}

It is unclear whether CART is secreted in a regulated fashion; there are indications that CART is released in a $\mathrm{Ca}^{2+}$-dependent way [10]. This is supported by the presence of CART immunoreactivity in dense core vesicles of axon terminals [11] and in secretory granules of islet cells [12]. CART is found in the circulation (mainly as CART 55-102) in the range of $10-100 \mathrm{pmol} / 1$ [13-15], i.e. at much lower concentrations than those tested in most functional experiments $(10-100 \mathrm{nmol} / \mathrm{l})$. Diurnal variations of CART levels have been reported [14].

Although specific binding for various CART peptides has been documented $[8,9,16]$, the putative receptor of CART has not yet been identified. In vitro studies suggest that CART binds to G-protein coupled receptors. In fact, there are indications that several CART receptor subtypes might exist. Some effects of CART are blocked by pertussis toxin treatment, suggesting a coupling to $\mathrm{G}_{\mathrm{i} / \mathrm{o}}$-proteins $[8,16]$. Other studies have reported that CART increases cyclic AMP levels, which rather points to the involvement of $G_{s}$ proteins. CART was also found to induce phosphorylation of cyclic AMP-response element-binding protein (CREB), insulin receptor substrate protein (IRS), protein kinase $\mathrm{B}$ (PKB), forkhead box protein O1 (FoxO1), p44/42-mitogen-activated protein kinase (p44/42 MAPK, also known as extracellular signal-regulated kinase [ERK1/2]) and p90 ribosomal S6 kinase (p90RSK) in INS- 1 cells or hypothalamic neurons $[8,17]$. The possibility that multiple CART receptor subtypes exist is strengthened by the observations that CART 55-102 and CART 62-102 display different potencies in some studies [8].

\section{Extrapancreatic effects of CART}

CART is widely expressed in the central nervous system. Although variable conclusions have been reported between studies, a consensus emerges that CART is anorexigenic. This role is supported by its distribution in brain regions controlling food intake, such as the arcuate nucleus (Arc), the lateral hypothalamus area, the paraventricular nucleus and the nucleus accumbens. Furthermore, observations have shown that administration of CART decreases food intake, whereas mice with global deletion of Cartpt ( $\operatorname{Cartpt}^{-/-}$mice) gain body weight $[8,11,18]$. Studies in humans corroborate 
these conclusions; missense mutation and single-nucleotide polymorphisms of Cartpt are associated with obesity [16, 19].

The Arc is a major centre controlling appetite. It contains two sets of neurons which reciprocally control food intake: the orexigenic neuropeptide Y (NPY)/Agouti-related peptide (AgRP) neurons, which promote food intake and reduce energy expenditure, and the adjacent anorexigenic proopiomelanocortin (POMC)/CART neurons, which inhibit food intake and increase energy expenditure. Fasting reduces Cart mRNA levels in various regions of the brain controlling food intake [16]. Interestingly, CART might mediate the effects of leptin since administration of leptin increases Cart mRNA levels in the Arc and hypothalamic regions. Moreover, in animals with disrupted leptin signalling, Cart mRNA is almost absent in the Arc.

CART does not only control food intake but it also regulates thermogenesis. Indeed, CART is expressed in arcuate neurons which project to the paraventricular nucleus and control the release of thyrotropin-releasing hormone (TRH). TRH in turn regulates pituitary gland secretion of thyroidstimulating hormone, which alters energy homeostasis by stimulating heat production by muscle and brown adipose tissue [8]. CART also plays a role in motor activity, reward and stress, and has functional properties of an endogenous psychostimulant $[8,19]$. Further, it is involved in anxietylike behaviour, depression, fear and startle behaviour $[8,11]$.

Outside the brain, CART is found in enteric neurons, in the vagal nerves, in pituitary endocrine cells, in adrenomedullary cells and in antral gastrin-producing G-cells [20,21]. CART is directly released into the hypothalamic-pituitary portal circuit and exerts multiple effects on the pituitary function [22]. Adrenals importantly contribute to circulating CART since adrenalectomy causes a 70\% reduction in blood CART levels in the rat [14]. CART may also control bone resorption since Cartpt $^{-/}$mice show signs of osteoporosis [13].

\section{CART and pancreatic islets}

CART has been shown to affect the function of the islets of various species. In this issue of Diabetologia, Abels et al [7] explored the possible role of CART in human and mouse islets in healthy conditions and in diabetes. In mice, rats and humans, CART is expressed in islet endocrine cells and in parasympathetic and sensory fibres innervating the islets $[20$, 21, 23]. The distribution of CART in islet cells is highly variable between species (Fig. 2). In the normal state, CART is expressed in rats in a subpopulation of delta- and beta cells [7, $21,24,25]$. In mice, it is also found in a subpopulation of beta cells but it is barely detected in delta cells. In humans, CART (identified as CART 55-102 by western-blot) is consistently expressed in beta- and alpha cells, contrary to what was found in mice and rats [7]. The expression pattern is altered by diabetes and CART expression is strongly upregulated in the beta cells of several animal models of type 2 diabetes, i.e. in dexamethasone-treated rats, Goto-Kakizaki (GK) rats, Zucker diabetic fatty (ZDF) rats, ob/ob mice, high fat diet fed mice and dominant-negative HNF1 $\alpha$ mice $[7,21,24]$. However, CART remains undetectable in alpha cells of diabetic rodent models [7]. In humans, diabetes increases CART expression in both alpha- and beta cells (Fig. 2).

Interestingly, CART expression is very variable between beta cells. Even in diabetic conditions, the percentage of CART-positive beta cells does not exceed $60 \%$. The reasons for this heterogeneity are unknown but this situation is reminiscent of the variability of placental lactogen-induced serotonin immunoreactivity in individual beta cells $[26,27]$, and of the variability in glucose responsiveness of individual beta cells $[28,29]$. Heterogeneity of proliferation, gene expression and the function of beta cells between islets as a result of differential blood flow has also been documented in the rat [30]. It is possible that glycaemia is a direct regulator of CART
Fig. 2 Distribution of CART immunoreactivity in islet cells of various species at the adult stage in normal (non-diabetic) conditions or in conditions of type 2 diabetes. Beta-, alpha- and delta cells are represented in the islet drawing as black, green and blue cell outlines, respectively. The level of CART expression is illustrated by the intensity of the red colour used to fill the cell. + , expressed; ++, strongly expressed; NT, not tested; $\uparrow$, personal communication (from N. Wierup, Lund University Diabetes Centre, Sweden)

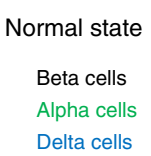

Rat

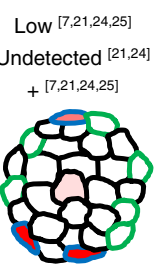

Type 2 diabetes

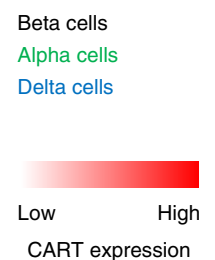

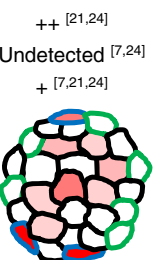

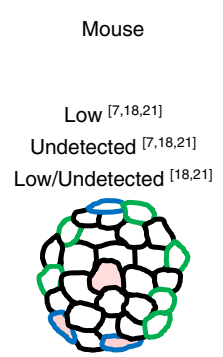

Human

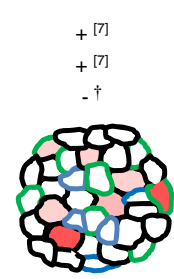

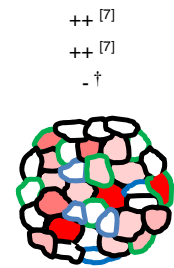


expression since experiments on dexamethasone-treated rats (as a model of type 2 diabetes) have shown that correction of hyperglycaemia using insulin normalised the upregulation of CART expression [7]. A role for CART in islet growth or islet cell differentiation is also possible since its expression is increased in some rodent islet cells during development [21].

Several groups have tested the effect of CART on the secretion of islet hormones (Table 1). In the rat, CART exerts variable effects on insulin secretion depending on the study, being inhibitory, stimulatory or lacking any effect $[21,24,31]$. However, it has been found that CART stimulates insulin release from mouse and human islets [7]. This acute effect of CART is associated with an increase in the frequency of glucose-induced oscillations in free cytosolic $\mathrm{Ca}^{2+}$ concentration $\left(\left[\mathrm{Ca}^{2+}\right]_{\mathrm{c}}\right)$ and a better synchronisation of $\left[\mathrm{Ca}^{2+}\right]_{\mathrm{c}}$ oscillations between islet subregions. Moreover, a $24 \mathrm{~h}$-exposure of mouse islet cells to CART (to mimic type 2 diabetes) has been found to stimulate insulin release. Interestingly, in the presence of GLP-1 or cyclic AMPproducing agents, CART 55-102 consistently amplifies insulin secretion from rodent islets in a protein kinase A (PKA)-dependent manner [7, 21, 24]. CART 55-102 also protects beta cells against glucotoxicity and promotes survival and induces proliferation of beta cells [17]. In addition, it inhibits glucagon secretion of human and mouse islets at low glucose [7], and modestly inhibits somatostatin secretion from rat islets [17, 24].

Together, these experiments highlight an important role of CART in islet function. This is further strengthened by the observation that $\mathrm{Cartpt}^{-/}$mice have impaired insulin secretion which may partly be due to a reduction in pancreatic duodenal homeobox 1 (PDX1) and glucose transporter 2 (GLUT2) expression [18]. Because of the beneficial effect of CART on islet function, Abels et al [7] speculate that the upregulation of CART in type 2 diabetes might reflect a homeostatic compensatory mechanism to overcome hyperglycaemia.

Table 1 Effect of 10-100 nmol/l CART on insulin, glucagon and somatostatin secretion by islets from various species

\begin{tabular}{llll}
\hline Effect & Rat & Mouse & Human \\
\hline $\begin{array}{lll}\text { Insulin secretion } \\
\quad \text { CART alone }\end{array}$ &,+- or 0 [21, 24, 31] & $+[7]$ & $+[7]$ \\
$\quad \begin{array}{l}\text { CART in combination } \\
\text { with GLP-1 or } \\
\quad \text { cAMP-raising agents }\end{array}$ & $+[21,24]$ & $+[7]$ & NT \\
$\begin{array}{c}\text { Glucagon secretion } \\
\text { CART alone }\end{array}$ & $-[24]$ & & \\
$\begin{array}{c}\text { Somatostatin secretion } \\
\text { CART alone }\end{array}$ & $-[21,24]$ & $-[7]$ & $-[7]$ \\
\hline
\end{tabular}

The effect of CART on insulin release was tested with or without GLP-1 or cyclic AMP-raising agents

CART 55-102 was assessed in most studies

+ , stimulation; -, inhibition; 0, no effect; NT, not tested

cAMP, cyclic AMP
Although the study by Abels et al [7] gives new insights into the effects of CART on islet function, there are still many questions that remain unanswered and require further investigation. For example, is CART released from islet cells and is it released in a regulated fashion? Does CART exert paracrine effects and what are these effects? How is CART expression regulated and why is it so heterogeneous between beta cells? By which mechanism does CART control insulin and glucagon secretion? Is the long-term effect of CART ( $\geq 24 \mathrm{~h}$ exposure) due to transcriptional effects, as shown in other systems $[32,33]$ ?

\section{Conclusion}

Overall, there are numerous indications that the effects of CART peptides, whether mediated by the central nervous system or the islets, are beneficial to combat obesity and type 2 diabetes. Moreover, CART and GLP-1 exert many similar effects [4] that, at least at the islet level, are additive. One major drawback of targeting CART might be the increase in fear and anxiety-like behaviour. However, these unwanted effects might possibly be avoided if they are mediated by different receptor subtypes than those producing the beneficial effects. Therefore, identification of CART receptors is urgently needed. Given the enormous public health burden of both obesity and type 2 diabetes, exploration of the pharmacotherapies which target CART peptides provides an exciting and challenging area for research.

Funding The author is supported by the Fonds National de la Recherche Scientifique (Brussels, grant PDR T.0124.15), the Actions de Recherche Concertées (ARC 13/18-051) from the French Community of Belgium and a EFSD/Boehringer Ingelheim grant. P. Gilon is Research Director of the Fonds National de la Recherche Scientifique, Brussels.

Duality of interest The author declares that there is no duality of interest associated with this manuscript.

Contribution statement The author was the sole contributor to this paper.

\section{References}

1. Schwartz MW, Seeley RJ, Tschop MH et al (2013) Cooperation between brain and islet in glucose homeostasis and diabetes. Nature 503:59-66

2. Steinbusch L, Labouebe G, Thorens B (2015) Brain glucose sensing in homeostatic and hedonic regulation. Trends Endocrinol Metab 26:455-466

3. Scarlett JM, Schwartz MW (2015) Gut-brain mechanisms controlling glucose homeostasis. F1000 Prime Rep 7:12

4. Skibicka KP (2013) The central GLP-1: implications for food and drug reward. Front Neurosci 7:181 
5. Sandoval DA, D’Alessio DA (2015) Physiology of proglucagon peptides: role of glucagon and GLP-1 in health and disease. Physiol Rev 95:513-548

6. Tuduri E, Lopez M, Dieguez C, Nadal A, Nogueiras R (2016) Glucagon-Like Peptide 1 Analogs and their Effects on Pancreatic Islets. Trends Endocrinol Metab 27:304-318

7. Abels M, Riva M, Bennet $\mathrm{H}$ et al (2016) CART is overexpressed in human type 2 diabetic islets and inhibits glucagon secretion and increases insulin secretion. Diabetologia. doi:10.1007/s00125016-4020-6

8. Rogge G, Jones D, Hubert GW, Lin Y, Kuhar MJ (2008) CART peptides: regulators of body weight, reward and other functions. Nat Rev Neurosci 9:747-758

9. Zhang M, Han L, Xu Y (2012) Roles of cocaine- and amphetamineregulated transcript in the central nervous system. Clin Exp Pharmacol Physiol 39:586-592

10. Murphy KG, Abbott CR, Mahmoudi M et al (2000) Quantification and synthesis of cocaine- and amphetamine-regulated transcript peptide (79-102)-like immunoreactivity and mRNA in rat tissues. J Endocrinol 166:659-668

11. Subhedar NK, Nakhate KT, Upadhya MA, Kokare DM (2014) CART in the brain of vertebrates: circuits, functions and evolution. Peptides 54:108-130

12. Wierup N, Bjorkqvist M, Kuhar MJ, Mulder H, Sundler F (2006) CART regulates islet hormone secretion and is expressed in the beta-cells of type 2 diabetes rats. Diabetes 55:305-311

13. Singh MK, Elefteriou F, Karsenty G (2008) Cocaine and amphetamine-regulated transcript may regulate bone remodeling as a circulating molecule. Endocrinology 149:3933-3941

14. Vicentic A, Dominguez G, Hunter RG, Philpot K, Wilson M, Kuhar MJ (2004) Cocaine- and amphetamine-regulated transcript peptide levels in blood exhibit a diurnal rhythm: regulation by glucocorticoids. Endocrinology 145:4119-4124

15. Bech P, Winstanley V, Murphy KG et al (2008) Elevated cocaineand amphetamine-regulated transcript immunoreactivity in the circulation of patients with neuroendocrine malignancy. J Clin Endocrinol Metab 93:1246-1253

16. Lau J, Herzog H (2014) CART in the regulation of appetite and energy homeostasis. Front Neurosci 8:313

17. Sathanoori R, Olde B, Erlinge D, Goransson O, Wierup N (2013) Cocaine- and amphetamine-regulated transcript (CART) protects beta cells against glucotoxicity and increases cell proliferation. J Biol Chem 288:3208-3218

18. Wierup N, Richards WG, Bannon AW, Kuhar MJ, Ahrén B, Sundler F (2005) CART knock out mice have impaired insulin secretion and glucose intolerance, altered beta cell mophology and increased body weight. Regul Pept 129:203-211

19. Vicentic A, Jones DC (2007) The CART (cocaine- and amphetamine-regulated transcript) system in appetite and drug addiction. J Pharmacol Exp Ther 320:499-506
20. Wierup N, Kuhar M, Nilsson BO, Mulder H, Ekblad E, Sundler F (2004) Cocaine- and amphetamine-regulated transcript (CART) is expressed in several islet cell types during rat development. J Histochem Cytochem 52:169-177

21. Wierup N, Sundler F (2006) CART is a novel islet regulatory peptide. Peptides 27:2031-2036

22. Larsen PJ, Seier V, Fink-Jensen A, Holst JJ, Warberg J, Vrang N (2003) Cocaine- and amphetamine-regulated transcript is present in hypothalamic neuroendocrine neurones and is released to the hypothalamic-pituitary portal circuit. J Neuroendocrinol 15 : 219-226

23. Kasacka I, Janiuk I, Lewandowska A, Bekisz A, Lebkowski W (2012) Distribution pattern of CART-containing neurons and cells in the human pancreas. Acta Histochem 114:695-699

24. Wierup N, Bjorkqvist M, Kuhar MJ, Mulder H, Sundler F (2006) CART regulates islet hormone secretion and is expressed in the beta-cells of type 2 diabetic rats. Diabetes 55:305-311

25. Jensen PB, Kristensen P, Clausen JT et al (1999) The hypothalamic satiety peptide CART is expressed in anorectic and non-anorectic pancreatic islet tumors and in the normal islet of Langerhans. FEBS Lett 447:139-143

26. Goyvaerts L, Schraenen A, Schuit F (2016) Serotonin competence of mouse beta cells during pregnancy. Diabetologia 59:1356-1363

27. Schraenen A, Lemaire K, de FG et al (2010) Placental lactogens induce serotonin biosynthesis in a subset of mouse beta cells during pregnancy. Diabetologia 53:2589-2599

28. Schuit FC, In't Veld PA, Pipeleers DG (1988) Glucose stimulates proinsulin biosynthesis by a dose-dependent recruitment of pancreatic beta cells. Proc Natl Acad Sci U S A 85:3865-3869

29. Salomon D, Meda P (1986) Heterogeneity and contact-dependent regulation of hormone secretion by individual B cells. Exp Cell Res $162: 507-520$

30. Lau J, Svensson J, Grapensparr L, Johansson A, Carlsson PO (2012) Superior beta cell proliferation, function and gene expression in a subpopulation of rat islets identified by high blood perfusion. Diabetologia 55:1390-1399

31. Colombo M, Gregersen S, Xiao J, Hermansen K (2003) Effects of ghrelin and other neuropeptides (CART, $\mathrm{MCH}$, orexin $\mathrm{A}$ and $\mathrm{B}$, and GLP-1) on the release of insulin from isolated rat islets. Pancreas 27:161-166

32. Sen A, Lv L, Bello N, Ireland JJ, Smith GW (2008) Cocaine- and amphetamine-regulated transcript accelerates termination of follicle-stimulating hormone-induced extracellularly regulated kinase $1 / 2$ and Akt activation by regulating the expression and degradation of specific mitogen-activated protein kinase phosphatases in bovine granulosa cells. Mol Endocrinol 22:2655-2676

33. Vrang N, Tang-Christensen M, Larsen PJ, Kristensen P (1999) Recombinant CART peptide induces c-Fos expression in central areas involved in control of feeding behaviour. Brain Res 818: 499-509 